\title{
In-vivo and In-Vitro Examination of the Effect of Lucilia Sericata Larvae and Secretions on the Bacteria in Open Wounds
}

\author{
Erdal Polat' (1), Dilek Bolaban² ${ }^{D}$, Serhat Sirekbasan ${ }^{3}$ (D) \\ 'Department of Medical Microbiology, İstanbul University-Cerrahpașa School of Medicine, İstanbul, Turkey \\ 2Department of Biotherapy Research and Development Laboratory, İstanbul University-Cerrahpașa School of Medicine, İstanbul, Turkey \\ ${ }^{3}$ Department of Medical Laboratory Techniques, Çankırı Karatekin University Eldivan Vocational School of Health Services, Çankırı, Turkey
}

ORCID iDs of the authors: E.P. 0000-0002-9463-9846; D.B. 0000-000I-7226-357X; S.S. 0000-000I-7967-3539.

Cite this article as: Polat E, Bolaban D, Sirekbasan S. In-vivo and In-Vitro Examination of the Effect of Lucilia Sericata Larvae and Secretions on the Bacteria in Open Wounds. Cyprus J Med Sci 2020; 5(2): II3-6.

\section{BACKGROUND/AIMS}

Maggot Therapy is an old method used to contribute to the debridement, disinfection and healing of chronic wounds. In this study, we examined the antimicrobial effect of Lucilia sericata larvae and secretion on the bacteria in open wounds both in in-vivo and in-vitro manner.

\section{MATERIAL and METHODS}

Samples were taken from 25 wounds belonging to 23 patients and were tested with bacteria cultures made to observe the bacterial variety before and after the Maggot Debridement Therapy (MDT). In addition, in in-vitro conditions the Lucilia sericata larvae secretion was examined against methicillin-resistant Staphylococcus aureus (MRSA), methicillin-sensitive Staphylococcus aureus (MSSA) and Pseudomonas aeuroginosa bacteria.

\section{RESULTS}

In the in-vivo section of our study in which we compared the bacterial variety before and after applying L. sericata larvae, we observed that there were reductions in bacterial load on the infected wounds especially the gram-positive bacteria. The data in the in-vitro section of our study in which we used solid and liquid broth media showed that the anti-bacterial effect changed according to the characteristics of the broth medium.

\section{CONCLUSION}

Maggot Therapy may be used in an efficient way in eliminating the pathogen bacteria in infected wounds with the help of its antibacterial activity.

Keywords: Antibacterial activity, larval therapy, Lucilia sericata, Maggot therapy, Methicillin-resistant, Staphylococcus aureus

\section{INTRODUCTION}

Maggot Therapy (sometimes called larval therapy) is the application of the live fly larvae to the wounds of the patient to help the debridement, disinfection, and eventually, to the healing. As a matter of fact, this method is a therapeutic wound myiasis whose reliability and efficiency is controlled in clinical conditions (I).

The Lucilia sericata larvae, which are used commonly in the treatment of open wounds, produce plenty of proteolytic enzymes, substances with antibacterial characteristics and different substances that ensure the granulation of the tissue ( 2 , 3). Many clinical reports provide us with the proof on the important effects of the larvae therapy used in the debridement, cleaning, and eliminating infection in many wounds that do not heal with traditional treatment methods (4-6).

The beneficial effects of using larvae in treating open wounds were first mentioned in 1557 (4). The larvae therapy which lately named as Maggot Debridement Therapy (MDT), was used in treating open wounds in 1930 for the first time and became more popular in time. It was used extensively until 1940 in the treatment of chronic and infected wounds. In 1940, the use of it decreased with the discovery of antibiotics and due to some difficulties in using it; and was ignored by the medical community at a great deal. However, the interest in MDT increased again because of the antibiotics being inad- 
equate in the treatment of infected chronic wounds because of the increasing antibiotic resistance incidence as of late 1990s (7).

Studies conducted in recent years showed that the secretions of the larvae contain at least two substances that have antibacterial characteristics. One of these substances is a hydrophobic peptide-like substance whose molecular weight is 3-10 kDa, and the other one is a hydrophilic substance of $<\mathrm{kDa}$. These substances shown to eliminate the infection by killing and stopping the growth of the microorganisms those cause infection in wounds (2).

The antibacterial efficiency of larvae secretions was investigated by many authors in in-vitro conditions, and their strong efficiency against many pathogenic bacteria was revealed (2,3). In addition to this, it was seen that the studies conducted on the effects of the MDT for various microorganisms that infect chronic wounds were insufficient.

Based on these findings, the materials from 25 wounds of 23 patients were evaluated to observe the bacterial variety before and after the MDT. In addition, the effect of the MDT against methicillin-resistant Staphylococcus aureus (MRSA), methicillin-sensitive Staphylococcus aureus (MSSA) and Pseudomonas aeuroginosa bacteria was also investigated in in-vitro conditions.

\section{MATERIAL AND METHODS}

The study was approved by the ethics committee of Istanbul University Cerrahpașa School of Medicine (34256/2013). Signed consent forms were obtained from all patients.

\section{Preparing the Sterile $L$. sericata Larvae}

A piece of liver was placed on the fly cages in which there were adult L. sericata colonies. After 3-4 hours, the liver was taken from the cage and the eggs on liver were collected. The eggs were separated and sterilized; and were then transferred to sterile liver agar. The agars containing eggs were incubated for $36-40$ hours at $25-30^{\circ} \mathrm{C}$. Within this time period, the larvae, which evolved to the $3^{\text {rd }}$ instar from the $2^{\text {nd }}$ instar, were taken into sterile containers to be used $(2,7)$.

\section{Obtaining Larvae Secretion}

The 4000 pcs of II.-III. instar sterile larvae produced in the laboratory were taken into a sterile I Lt beaker and $2 \mathrm{~mL}$ distilled

\section{Main Points:}

- Maggot debridement therapy (MDT) has been shown to be an effective method for cleaning chronic wounds and granulation formation.

- Lucilia sericata larvae and their secretions may be used in an efficient way in eliminating the pathogen bacteria in infected wounds.

- Lucilia sericata larvae and their secretions also has the advantage of eliminating the active bacteria in wounds with their antibacterial effects against increasing resistance.

- It is important to encourage the widespread use of the Lucilia sericata larvae, which may play an active role in healing problematic wounds. water was added for 4 times in total with I-hour intervals. Five hours later the last distilled water was added, the accumulated larvae secretion was taken and filtered through $0.45 \mu \mathrm{m}$ injector filters to purify the possible bacteria contamination.

\section{The in-vitro antibacterial effect of the larvae secretions}

The antibacterial efficiency of sterile larvae secretion was investigated on two $S$. aureus origins that are resistant and sensitive to methicillin and one $P$. aeuroginosa bacteria. For bacterial cultures, enrichment was performed overnight at $37^{\circ} \mathrm{C}$ in $5 \mathrm{~mL}$ Tryptic Soy Broth (TSB). From each bacteria dilution that was prepared as having $10^{2}$ and $10^{4}$ cultural density, $0.1 \mathrm{~mL}$ was taken and added to the tubes that had $2 \mathrm{~mL}$ TSB and $2 \mathrm{~mL}$ larvae secretion. For positive growth control, $2 \mathrm{~mL} \% 0.9 \mathrm{NaCl}$ and 0.1 $\mathrm{mL}$ bacteria dilution were added instead of larvae secretion. For negative control, $4 \mathrm{~mL} 0.9 \% \mathrm{NaCl}$ and $0.1 \mathrm{~mL}$ bacteria dilution were added.

The samples that were prepared were incubated overnight at $37^{\circ} \mathrm{C}$ and $0.1 \mathrm{~mL}$ was spread to chocolate agar for the purpose of counting colonies.

\section{The Selection of the Patients}

A total of 23 patients who were sent to our unit from various hospitals and clinics with MDT demand (7 females, 16 males; mean age 55.7 years; range 29 to 77 years) were treated with larvae therapy. The clinical characteristics of the patients are given in Table I.

\section{Applying Sterile Larvae to the Wounds}

In the I. instar, the larvae of the L. sericata fly was applied to the wounds of the patients in our study group. In superficial wounds, the larvae were applied to $1 \mathrm{~cm}^{2}$ area to contain 8-I0 larvae; and in deep wounds, more larvae were placed on the wound area directly. The larvae were covered with sterile sponge and it was recommended to the patient to change it frequently to enable necrotic drainage. After the larvae were kept on the wound for 48-72 hours, they were removed.

\section{Definition of the Bacteria in the Samples Taken from the Wound Tissues}

Before and after each MDT application, swab samples were taken from the open wounds of the patients; and were evaluated in bacteriological terms. In addition, the antibiotic sensitivity

\begin{tabular}{|c|c|c|}
\hline & Number & $(\%)$ \\
\hline \multicolumn{3}{|l|}{ Underlying disease } \\
\hline Diabetes & 16 & $(69.56)$ \\
\hline Venous stasis & । & $(4.35)$ \\
\hline Buerger & । & $(4.35)$ \\
\hline Vulva cancer & । & $(4.35)$ \\
\hline No disease & 3 & $(13.04)$ \\
\hline Osteomyelitis + diabetes & । & $(4.35)$ \\
\hline \multicolumn{3}{|l|}{ Wound area } \\
\hline Feet & 22 & (88) \\
\hline Other (perineum, abdomen, armpit) & 3 & $(12)$ \\
\hline
\end{tabular}


tests of the isolated origins were investigated in line with the recommendations of the Clinical and Laboratory Standards Institute (CLSI).

\section{Statistical Analysis}

The statistical analysis of the results of the study was made with the IBM Statistical Package for the Social Sciences 21.0 version (IBM Corp.; Armong, NY, ABD) and with Chi-Square tests. The frequency, percentage, average and median values were computed for definitive statistics.

\section{RESULTS}

In the in-vitro section of our study, the effect of larvae secretion on MRSA, MSSA and P. aeuroginosa bacteria was tested in Mueller Hinton agar and positive results were not obtained. When the same trial was performed in tryptic soy broth, it was determined that the colony numbers of MRSA, MSSA and P. aeuroginosa decreased at a rate of $50 \%$.

In in-vivo section of our study, when we consider the bacteriological examination of the samples taken from all the wounds before the sterile larvae application, among the isolated bacteria we detected that there were seven different Gram-negative bacteria origins and four different Gram-positive bacteria origins (Table 2).

In our study, after the MDT, no bacteria reproduced in two wounds with MRSA, in four wounds with MSSA and in three wounds with Enterococcusspp. It was observed that the number of colonies decreased by $75 \%$ in six wounds with MSSA, the number of colonies increased by $50 \%$ in one wound and remained unchanged in one wound. In 10 of the wounds in which Proteus mirabilis and P. aeruginosa reproduced, and in two of the wounds in which Escherichia coli and Klebsiella spp. reproduced, no additional bacteria reproduction was observed. In four of the wounds in which $P$. mirabilis, $P$. aeruginosa, Enterobacter cloaceae and Serratia marcescens reproduced, the number of colonies decreased at a rate of $50 \%$; and in the wounds in which E. coli reproduced, the number of colonies decreased at a rate of $25 \%$. In two of the wounds in which Klebsiella spp. reproduced, the number of colonies did not change.

\begin{tabular}{|lcc|}
\hline TABLE 2. The bacteria isolated form the wounds & & \\
Bacteria & Number & $(\%)$ \\
\hline Acinetobacterspp. & 1 & $(2.17)$ \\
Enterobacter cloaceae & 1 & $(2.17)$ \\
Enterococcus spp. & 3 & $(6.52)$ \\
Escherichia coli & 3 & $(6.52)$ \\
Klebsiella spp. & 3 & $(6.52)$ \\
Coagulase-negative staphylococci & 7 & $(15.21)$ \\
Proteus mirabilis & 6 & $(13.04)$ \\
Pseudomonas aeruginosa & 6 & $(13.04)$ \\
Staphylococcus aureus & 14 & $(30.43)$ \\
Serratia marcescens & 1 & $(2.17)$ \\
Streptococcus agalactiae & 1 & $(2.17)$ \\
\hline
\end{tabular}

\section{DISCUSSION}

Larva therapy is used in treating the wounds that are not healed for long years. Larvae ensure that the necrotic tissue is debrided through biochemical and mechanical ways, the inflammation is decreased, and granulation tissue is stimulated $(8,9)$. In addition to these, many compounds that have antibacterial effects are secreted as well as this complex interaction. Although studies have been conducted to determine what these compounds are, the exact mechanism has not been fully uncovered yet $(I 0, I)$.

The use of larvae is gaining importance due to the difficulties in managing chronic wounds infected because of the increasing antibiotic resistance incidence in our present day.

It was determined that $L$. sericata larvae killed the bacteria that have pathogenic properties especially like $S$. aureus and Group $A$ and $B$ streptococci or inhibit their growth in in-vitro conditions, and also had some effects against Pseudomonas spp.; however, they did not have any effects against E. coliand Proteusspp. (I2). However, Jaklic et al., reported that larvae had very little effects against Proteus spp. (I3).

Daeschlein etal.(14), used a method to determine the bactericidal effects of $L$. sericata larvae secretions in in-vitro conditions, and reported that larvae secretions had all of the properties of an antiseptic. Bexfield et al. (10), conducted a study and proved that L. sericata larvae had antibacterial efficiencies against MRSA in in-vitro conditions. In addition, they also showed that the larvae secretions were influential on some bacteria like Streptococcus pyogenes, Enterococcus faecalis, Clostridium welchii, P. vulgaris, Streptococcus pneumoniae and E. coli in in-vitro conditions.

Kerridge et al. (3) investigated the antibacterial effects of larvae in their in-vitro study and observed that the reproduction of MRSA and Streptococcus pyogenes bacteria was inhibited, and there was a limited effect against $P$. aeruginosa. In addition, they also determined that the antibacterial efficiency of the larvae would change depending on the broth medium used in the trial being solid or liquid.

In the in-vitro section of our study, the effects of larvae secretions were tested on MRSA, MSSA and P. aeruginosa in Mueller Hinton agar; however, no positive results were obtained. The same trial was tested with Tryptic Soy broth and it was determined that the number of the colonies of these bacteria reduced at a rate of $50 \%$. The data we obtained in the in-vitro section of our study by using solid and liquid broth medium show that the antibacterial effect varied according to the properties of the broth medium. These findings of our study are consistent with the results of previous studies.

Jaklic et al. (13) investigated the bacterial variety in-vivo conditions as before and after the MDT in 30 patients. According to this study, bactericidal effects were observed against Group C streptococci, Group G streptococci, Bacteroides fragilis, Citrobacter freundii, Klebsiella spp., Peptococcus spp., Prevotella bivia, Serratia marcescens and Streptococcus agalactiae, and these bacteria did not reproduce when the treatment was ended. It was also determined that the colony numbers of the coagula negative streptococci, Citrobacter koseri, Klebsiella oxytoca, $P$. aeruginosa and $S$. aureus decreased at a serious level; 
however, Enterococcus faecalis, Morganella spp., Peptostreptococcus assacharolyticus, Porphyromonas spp. and Providencia rettgeri increased in terms of the colony count when compared with the pre-treatment period.

In our study, after the MDT, no bacteria reproduced in two wounds with MRSA: in four wounds with MSSA and in three wounds with Enterococcus spp. It was observed that the number of the colonies decreased at a rate of $75 \%$ in six wounds with MSSA; increased in I wound at a rate of $50 \%$; and remained the same in one wound. In our study, no bacteria reproduced in 10 of the wounds in which $P$. mirabilis and $P$. aeruginosa reproduced before and in two of the wounds in which E. coli and Klebsiella spp. reproduced. In four of the wounds in which $P$. mirabilis, $P$. aeruginosa, E. cloaceae and $S$. marcescens reproduced, the number of the colonies decreased at a rate of $50 \%$; and in two of the wounds in which $E$. coli reproduced, the number of the colonies decreased at a rate of $25 \%$. The number of the colonies did not change in two of the wounds in which Klebsiella spp. reproduced.

We may conclude that when the variety in bacterial pathogens in infected wounds is considered, the ever-increasing antibiotic resistance will rank the first among the factors that might affect the wound management. As a result, we believe that the MDT performed with the L. sericata larvae will be extremely useful in eliminating the active bacteria in wounds with their antibacterial effects against this increasing resistance.

Ethics Committee Approval: Ethics committee approval was received for this study from the ethics committee of Istanbul University Cerrahpașa School of Medicine Ethics Committee of Clinical Research (34256/2013).

Informed Consent: Written informed consent was obtained from patients who participated in this study.

Peer-review: Externally peer-reviewed.

Author Contributions: Concept - E.P., D.B.; Design - E.P.; Supervision - E.P., S.S.; Resources - E.P., S.S.; Materials - D.B., S.S.; Data Collection and/or Processing - E.P., D.B.; Analysis and/or Interpretation - E.P., D.B., S.S.; Literature Search - S.S.; Writing Manuscript - D.B., S.S.; Critical Review - E.P.

Acknowledgements: We appreciate the support of Scientific Research Projects Coordination Unit of Istanbul University.
Conflict of Interest: Authors have no conflicts of interest to declare.

Financial Disclosure: The authors declared that this study has been supported by Scientific Research Projects Coordination Unit of Istanbul University (Project number: 3028).

\section{REFERENCES}

I. Sherman RA. Mechanisms of maggot-induced wound healing: what do we know, and where do we go from here? Evid Based Complement Alternat Med 2014; 2014(2): 592419. [Crossref]

2. Huberman L, Gollop N, Mumcuoglu KY, Block C, Galun R. Antibacterial properties of whole body extracts and haemolymph of Lucilia sericata maggots. J Wound Care 2007; 16(3): 123-7. [Crossref]

3. Kerridge A, Lappin-Scott H, Stevens JR. Antibacterial properties of larval secretions of the blowfly, Lucilia sericata. Med Vet Entomol 2005; 19(3): 333-7. [Crossref]

4. Chan DC, Fong DH, Leung JY, Patil NG, Leung GK. Maggot debridement therapy in chronic wound care. Hong Kong Med J 2007; I3(5): 382-6.

5. Thomas S, Jones M, Wynn K, Fowler T. The current status of maggot therapy in wound healing. Br J Nurs 200I; IO(22 Suppl): S5-8, SIO, S2. [Crossref]

6. Whitaker IS, Twine C, Whitaker MJ, Welck M, Brown CS, Shandall A. Larval therapy from antiquity to the present day: mechanisms of action, clinical applications and future potential. Postgrad Med J 2007; 83(980): 409-13. [Crossref]

7. Mumcuoglu KY. Clinical applications for maggots in wound care. Am J Clin Dermatol 200I; 2(4): 219-27. [Crossref]

8. Watts R. Evidence summary: wound management: larval therapy. Wound Practice Res 2016; 24: 180-2.

9. Sherman RA. Maggot therapy takes us back to the future of wound care: new and improved maggot therapy for the 2lst century. J Diabetes Sci Technol 2009; 3(2): 336-44. [Crossref]

10. Bexfield A, Nigam Y, Thomas S, Ratcliffe NA. Detection and partial characterisation of two antibacterial factors from the excretions/ secretions of the medicinal maggot Lucilia sericata and their activity against methicillin-resistant Staphylococcus aureus (MRSA). Microbes Infect 2004; 6(14): 1297-304. [Crossref]

II. Thomas S, Andrews AM, Hay NP, Bourgoise S. The anti-microbial activity of maggot secretions: results of a preliminary study. J Tissue Viability 1999; 9(4): 127-32. [Crossref]

12. Bonn D. Maggot therapy: an alternative for wound infection. Lancet 2000; 356(9236): I174. [Crossref]

13. Jaklic D, Lapanje A, Zupancic K, Smrke D, Gunde-Cimerman N. Selective antimicrobial activity of maggots against pathogenic bacteria. J Med Microbiol 2008; 57(P+ 5): 617-25. [Crossref]

14. Daeschlein G, Mumcuoglu KY, Assadian O, Hoffmeister B, Kramer A. In vitro antibacterial activity of Lucilia sericata maggot secretions. Skin Pharmacol Physiol 2007; 20(2): II2-5. [Crossref] 